\title{
Street Children of Udaipur: Demographic Profile and Future Prospects
}

\author{
Dharam Singh, Nishtha Sareen, Abhishek Ojha and Devendra Sareen \\ Department of Pediatrics, R.N.T. Medical College, Udaipur Rajasthan, India \\ E-mail: <nishtha_sareen@yahoo.com>
}

KEYWORDS Developing Country. Street Children. Demographic Profile. Future

\begin{abstract}
Street children, still remain an unsolved problem in the developing country like ours. They lag behind in their socio-cultural, psychological, physical and mental development in comparison to normal children. Hence, this study has been under taken to find out the socio-cultural background, ecological factors and various problems faced by these children. This cross sectional study conducted in and around Udaipur city included 200 street children chosen randomly. After obtaining a detailed history regarding their caste, profession of their parents, family and environmental history, a detailed assessment of child labour was done. Special emphasis was laid upon child abuse, factors responsible for compelling them to adopt child labour and life style of these children. All of them were subjected to physical examination and signs of occupational hazards. Data analysis was done. We concluded that the street children were subjected more frequently to child abuse, were addicted to gutakha and tobacco and were working at a remote place from their house and not getting adequate shelter. They were not well entertained and were not satisfied with their owner's attitude. They were exposed to occupational hazards, deficiency diseases and had ambition to become a good citizen of the country. So, these street children must be provided tender care and emotional support and we must empower their educational and co-curricular activities, so that they attain a secure future.
\end{abstract}

\section{INTRODUCTION}

Street children is common problem of developing countries like ours it eventually impairs the personality and creativity of Children. The global efforts for preservation of child rights and protection of them from child labour are coming on first priority of every nation. It is recommended to eliminate child labour and identify 100 most child labour endemic districts in 11 states of the country \{Chouhan and Sharma 1997\}. Street children can be found easily in Udaipur in industries, factories, hotels and restaurants, dhabas, halwai shops, automobile and engineering workshops, building and construction, brick making, garbage collection, forestation, Cattle grazing, agriculture, mining operations, weaving, book binding etc. Many of the children are engaged as domestic servant too.

In this tribal district with a low literacy rate the parents of the street children are illiterate and even upto the extent of complete illiteracy in almost 95\% of them \{Khatu 1993\}. The parents of child labourers do not have positive attitude towards education of these teenagers, that is why diverting these working children towards education is a challenging task. Due to poverty and illiteracy, these street children are living in poor environmental condition and are not health con- scious. Family dispute and less love and affection by parents leads to hazardous habits of these children and most of them are exposed to occupational and health hazards (Shrivastava 2006).

All these factors make them vulnerable to deficiency, contagious and communicable diseases (Patel 2006). These not only affect the physical development of the child but mental development also.

The present study has been planned to assess the demographic profile, socio cultural backgrounds, health status and occupational hazards of street children of Udaipur and to find out various ways to improve their health status and lifestyle.

\section{METHODOLOGY}

This cross sectional study was planned to study the various demographic, socio-cultural factors and to assess the health status and occupational hazards of the street children in Udaipur. For this 200 street children working in various factories, restaurant, dhabas, tea stalls and small industries were interviewed. After gaining the confidence of the street child a detailed history was obtained. With the help of questionnaires contained in the performa the dietary pat- 
tern, history of the any illness in the past, history of any communicable disease was obtained in details. The family history was obtained regarding profession of parents, their educational status. History of any addiction in the family was also taken in account. The personal history of each and every child was enquired specially about drug addiction, the factors responsible for becoming street child, their mode of entertainment and their communication with others. They were also asked how they felt about the owner's attitude. The special points asked in history were factors compelling him to become a street child, working hours in a day, type of shelter taken, interaction with other street children, mode of entertainment, distance of working place from home, mode of celebration of festivals, whether he was permitted to go to home and the history of child abuse.

After the history, a detailed physical examination of each child was conducted, including measurement of anthropometry. Weight of each child was estimated by a portable weighing machine after eliminating the zero error. Height was assessed by keeping the child in a standing position and measuring the distance from crown to heel. The head circumference was accurately measured by a non-stretchable tape by cross tape technique. The chest circumference was measured at the level of the nipple by the similar tape. Wherever indicated, mid arm circumference was measured from the left arm between the acromion and olecranon processes.

Each child was examined thoroughly for any deficiency disease like Vitamin A deficiency by examination of bulbar conjunctiva and cornea. Vitamin D deficiency was estimated by clinical signs of rickets in the form of broadening of wrist and costo chondral beading. Anemia was assessed by examination of palpebral conjunctiva, oral mucosa, palms and generalised pallor. Important signs of any communicable or contagious disease were noted like rash, enanthemas, conjunctival congestion, pustules etc. Relevant systemic examinations was also conducted in each child in details. The personal hygiene of each child was assessed specially the condition of hair, nails and teeth. Any signs of occupational hazards were also noted in details. All the observations were recorded in a printed protocol and data analysis was done. Necessary treatment was provided to each and every child.

\section{RESULTSAND DISCUSSION}

All the children in the present study were between 8-14 yrs. of age. Similar finding have been reported by other workers \{(Shrivastava, 1995 and Sarumathy, 1999\}. Majority of the street children were males $(71 \%)$ because the parents usually insist the male offspring to work as a labourer at a place far away from the home. Similar finding have been reported by Kriplani (1989) and Khakhad (1993). In our study the street children belonged to OBC (60\%), Schedule Tribe (18\%), Schedule Caste (14\%) and other caste $(8 \%)$. This finding is further supported by previous workers (Chauhan and Sharma 1997, 1998 and Sarumathy 1999). Poverty still exists in these caste and most of them are landless and agricultural labourers. Hence the children are compelled to become child labourers.

Only $8 \%$ of the fathers and $2 \%$ of the mothers of these children had primary education. This finding is in accordance with the findings of Sarumathy (1999). Kutty et al. (1989) Raynold (1991) and Shrivastava (1995). They have blamed poor educational status of the parents as an important factor in etiology of child labour. They stated that early marriages and excess workload in these families are attributing to poor education in them. We observed that $76 \%$ of the street children were living in joint families and only $24 \%$ in nuclear families. Living in a joint family imposes economical burden on the family that is why these teenagers are compelled to adopt child labour. $6 \%$ of the cases under study had step parents. It was important to note that this was a significant factor attributing to child abuse.

\section{Child Abuse}

Child abuse was same in $30 \%$ of these children. Physical abuse in 26\%, sexual abuse in $3 \%$ and other abuse in $1 \%$. In literature most of the workers have reported physical abuse as a very important finding in child mal treatment. They have reported that even this maltreatment is so aggressive that at times children run away from homes. These findings are also supported by Jain (2007) and Nadeem et al. (2007). Regarding sexual abuse most of the workers have a common opinion that it is under reported. We have to gain confidence of the child labours to completely visualize the spectrum of the iceberg of sexual abuse. These findings are also supported by Amla (2007) and Mohsin (2007). 


\section{Addiction and Child Labour}

$98 \%$ of fathers and $70 \%$ of the mothers of these children were addicted. Among street children also majority was addicted to Gutakha (92\%), Tobacco (65.5\%), Smoking (33.5\%) and Alcohol (01\%) as clearly indicated by Table 1 .

Table 1: Pattern of addiction in street children.

\begin{tabular}{lrc}
\hline Type of addiction & No. & Percentage \\
\hline Gutakha & 184 & 92.0 \\
Tobacco & 131 & 65.5 \\
Smoking & 67 & 33.5 \\
Alcohol & 02 & 01.0 \\
\hline
\end{tabular}

Previous workers also reported that Gutakha and Tobacco addiction is the commonest mode of addiction in these children followed by Ganja, Bhang, Cigarette and Liquor.

Only $21 \%$ of children under study had gone to school one time or other. Poor educational status of the parents and excess work load on the mothers are the contributing factors for this. Kutty and Kumari (1989) agree to our findings. Raynolds (1991), Shrivastava (1995), Shah (1996) have also blamed poverty, illiteracy of the parents as the root cause of poor scholastic achievement of these children.

Dhabas and small hotels 46\%, Tea stalls 20\%, Small factories 18\%), Small shops 9\%) and Daily wages sites $(9 \%)$ were the commonest sites of working of the street children. As this is shown in Table 2.

Table 2: Sites of child labour

\begin{tabular}{lcc}
\hline Site of the child labour & No. & Percentage \\
\hline Dhabas and small hotels & 92 & 46.0 \\
Tea stalls & 40 & 20.0 \\
Small factories & 32 & 16.0 \\
Small shops & 18 & 9.0 \\
Daily wages & 18 & 9.0 \\
\hline
\end{tabular}

Bura (1992) and Sekar (1993) have also reported that most of the child labours were working at places like brass, lock, pottery, weaving, gem polishing industries, they also claimed that this environment creates several problems to the child labour in the form of polluted environment and physical strain.

Why adopted child labour? the answer was poverty $(53 \%)$, family circumstances $(24.5 \%)$, no interest in studies $(20.5 \%)$ persuation by others $(7 \%)$ and other reasons $(35 \%)$. Other workers have also reported that socio economic problems play a very crucial role in augmenting child labour. Subsequently, they are supported by Sarumathy (1999) who in his study has reported that their parents are mostly landless poor labours.

Most (55\%) of these children had to work 1214 hrs. daily, while (32\%) were working 8-12 hrs. daily and only $13 \%$ were working less than $8 \mathrm{hrs}$. a day. Previous workers have also supported our finding. The street children employed in industries have to work for long hours even during the night, which is hazardous for them. They have further documented that this may further affect their intellectual development adversely. Most of the children were working in other cities or town (48\%), same city (39\%) and at a walking distance (13\%). These children were taking shelter in night at the site of labour $(77 \%)$ or house of the owner $(23 \%)$.

\section{Modes of Entertaiment}

Most of the children entertained themselves by seeing television (52\%). Others entertained by listening to radio (38\%), playing games (13\%) and other modes (7\%). As these children have to work for a long time and are working in a remote area so they can not interact or play with the peers of the same age and can only enjoy limited modes of entertainment. Further, these children celebrated the festivals with other children at the same site of working $(59 \%)$, different sites of working $(29 \%)$ and at their homes with family members (12\%) only.

\section{Attitude Towards the Owner}

Only (23\%) children in the study group were satisfied with the attitude of the owner. Rest (77\%) were not satisfied. The reason is obvious, prolonged hours of working and not able to celebrate festivals with family and on the top of it child abuse, all these factors perpetuate a negative attitude of the street child towards the owner. Our finding is strengthened by Shrivastava (2006).

Regarding immunization BCG scar was present in $13.5 \%$ of cases Patel (2006) and Gupta (2007) have also reported poor immunization in these children due to poverty, ignorance and lack of education in their families. 


\section{Morbidity Pattern}

Table 3 denotes morbidity pattern of these children. Anemia, malnutrition, Vitamin A deficiency and dental caries were commonly observed in the children. Our finding is supported by Patel (2006), who reported malnutrition and anemia in majority of the street children in their study. These morbidities are as a result of poor diet, poor hygienic condition and ignorance of these children regarding nutritive food.

Table 3: Morbidity pattern among the children

\begin{tabular}{lrc}
\hline Moribidity & No. & Percentage \\
\hline Anemia & 144 & 72.0 \\
Vitamin A deficiency & 74 & 37.0 \\
Other vitamins deficiency & 64 & 32.0 \\
Malnutrition & 142 & 71.0 \\
Skin disorders (Boils, & 112 & 56.0 \\
$\quad$ Scabies, fungal infections & & \\
Dental caries & 99 & 49.5 \\
Systemic diseases & 18 & 9.0 \\
\hline
\end{tabular}

$26 \%$ of these children had fungal infection of skin and nails while $14 \%$ had injuries in hand and feet as occupational hazards. Our finding is in accordance with the findings of Gupta (2007) who have also reported these occupational hazards in their study. Prolonged hours of working specially in unhygienic conditions makes these children vulnerable to occupational hazards.

\section{Future Prospects}

As shown in Table 4, 33\% of them wanted to become doctor, $29 \%$ policeman, $16 \%$ businessman, $15.5 \%$ engineer and only $6.5 \%$ wanted to continue the same profession.

Table 4: Future prospects

\begin{tabular}{lcc}
\hline Want to become & No. & Percentage \\
\hline Doctor & 66 & 33.0 \\
Policeman & 58 & 29.0 \\
Businessman & 32 & 16.0 \\
Engineer & 31 & 15.5 \\
Continue same profession & 13 & 6.5 \\
\hline
\end{tabular}

Recently Thacker (2007) in his presidential address has stressed upon careful understanding and multi disciplinary coordination between various agencies dealing with child welfare to make these needy teenagers a good citizen of the country.

\section{CONCLUSIONAND RECOMMENDATIONS}

We conclude from the present study that $30 \%$ of the street children were subjected to child abuse. They were addicted to Gukakha (92\%) and Tobacco $(65.5 \%)$ were working at a remote place from their house $(48 \%)$ and were not getting adequate shelter $(77 \%)$. History of previous schooling was obtained in minority $(21 \%)$ and $6 \%$ had step parents. Majority of them belonged to joint families (76\%). They were not well entertained (80\%), and were not satisfied with behaviour of their owner (77\%). They were exposed to occupational hazards (40\%) and majority of them $(93.5 \%)$ had ambition to become good citizen of country.

Based on these observations we recommend that:

(a) Street children must be provided tender care and emotional support and good nutritive diet so that they are not exposed to occupational and health hazards.

(b) They must be motivated for admission in child labour school so that their educational and curricular activities can be empowered.

(c) Health education and knowledge of personal hygiene must be imparted to street children so that they are at par with other children of same age group and can attain their destination to have a secure future and become to a good citizen of our country.

(d) Achieving these targets requires careful understanding empathy and multi disciplinary coordination between various agencies that deal with child welfare.

(e) Universal compulsory primary education and improvement in socioeconomic status can eradicate evil of child labour.

(f) Focus group discussions are the best method for creating a conducive environment for eliminating information from children on child abuse.

(g) Child protection services must be provided at government level and various non-government organizations, these should further be coordinated with Department of Woman and Child Welfare.

(h) Advocacy and protection through the government must be provided against this Human Rights Violation against these helpless children.

(i) Pediatricians need to be sensitized to recog- 
nize child abuse or neglect and to incorporate knowledge of various aspects and the skills to address this in their activities.

\section{REFERENCES}

Amla Indira 2007. Sexual abuse Exploitation and Traffiking of children. The Mysore experience. In Abstracts of Sourvenir published in 44th National Conference of IAP.

Bura N 1992. Child Labour in the lock industry of Aligarh. Child Labour Series; Noida: CLC, NLI.

Chouhan VL, Sharma V 1997. Behavioural peculiarities of girl child labourers. Psycho-lingua, 27(2): 103-106.

Chouhan VL, Khatik RA 1988. A study of insecurity adjustement and Juvenile Delinquency among Street teenagers. The Social Profile, 2(2): 79-83.

Gupta DK. 2007. Socio Demorgraphic and Nutritional Correlated of Child labour in Urban area of Meerut. In Abstracts of Souvenir Published in 44th National Conference of IAP.

Jain Dipty 2007. The magnitude of child abuse by Indian parents. In Abstracts of Souvenir Published in 44th National Conference of IAP.

Khatu KK 1993. Working children in India. A Child Labour Series, Noida: NLI.

Khakhad CP1993. Patient child relations and the feelings of acceptance and rejection experience in children. Prachi Journal of Psycho Cultural Dimensions, 9(1): 21-24.

Kriplani MB 1989. Effective parental communication with children. The Indian Journal of Social Work, 50(4): 423-433.

Kutty Krishnana AC, Kumari KS 1989. Status of women in rural labour household. Journal of Rural Development, 8: 661-662.

Mohsin Nadeem 2007. Child abuse in India. An analytic study. In Abstracts of the Souvenir Published it in 43rd National Conference of IAP.

Patel SK 2006 Child labour in Agrabati making in slum area of Nagpur. In Abstracts of the Souvenir Published it in 43rd National Conference of IAP.

Raynolds MM 1992. Society Economy and Education of the Deprived. Delhi: Anupama Publishers.

Sarumathy M 1999. The child labour issue and the implementation of child labour elimination programme. A case study. Journal of Community Guidance and Research, 16(2): 201-209.

Sekar YR 1993. Child Labour Bin the Match Industry of Sivakasi. Child Labour Series, Noida: CLS, NLS.

Shah F 1996. Schedule Tribe Child Labour. Udaipur: Shiva Publishers Distributors.

Shrivastava M 1995. Drug abuse amongst street children. Perspective in Social Work, 10(1): 11-17.

Shrivastava SP 2006. Study of Health problems in and around in Patna. In Abstracts of the Souvenir Published in 43rd National Conference of IAP.

Thacker Naveen 2007 Presidential address. Indian Pediatrics, 44(1): 3 . 